\title{
Sound, materiality and embodiment challenges for the concept of 'musical expertise' in the age of digital mediatization
}

Convergence: The International Journal of Research into New Media Technologies 2015, Vol. 21(3) 294-300 (C) The Author(s) 2015 Reprints and permission: sagepub.co.uk/journalsPermissions.nav DOI: I0.II77//3548565I5579837 con.sagepub.com

@SAGE

\section{Steffen Lepa}

Technische Universität Berlin, Germany

\section{Anne-Kathrin Hoklas}

Technische Universität Berlin, Germany

\section{Hauke Egermann}

Technische Universität Berlin, Germany

\section{Stefan Weinzierl}

Technische Universität Berlin, Germany

\begin{abstract}
Within academic music research, 'musical expertise' is often employed as a 'moderator variable' when conducting empirical studies on music listening. Prevalent conceptualizations typically conceive of it as a bundle of cognitive skills acquired through formal musical education. By implicitly drawing on the paradigm of the Western classical live concert, this ignores that for most people nowadays, the term 'music' refers to electro-acoustically generated sound waves rendered by audio or multimedia electronic devices. Hence, our article tries to challenge the traditional musicologist's view by drawing on empirical findings from three more recent music-related research lines that explicitly include the question of media playback technologies. We conclude by suggesting a revised musical expertise concept that extends from the traditional dimensions and also incorporates expertise gained through ecological perception, material practice and embodied listening experiences in the everyday. Altogether, our contribution shall draw attention to growing convergences between musicology and media and communications research.
\end{abstract}

Corresponding author:

Steffen Lepa, Technische Universität Berlin, Audio Communication Group (Sekr, EN-8), Einsteinufer I7c, Berlin D-I0587, Germany.

Email: steffen.lepa@tu-berlin.de 


\section{Keywords}

Ability, audio, devices, generations, headphones, literacy, loudspeakers, musicology, playback, skills

\section{Introduction}

The notion of "musical expertise" has a long tradition in academic music research. Laboratory experiments, personal interviews, focus groups, ethnographies or survey studies often employ it as a 'moderator variable' when conducting research on everyday musical experiences. Prevalent theoretical conceptualizations comprise several dimensions of cognitive-perceptual skills that are assumed to be ontogenetically acquired through formal musical training or by playing a musical instrument (Hallam and Prince, 2003; Ollen, 2006). Accordingly, musical expertise is then determined by examining individual dispositions like 'being an amateur or professional musician' (Pearce et al., 2010), 'years of musical training' (Farbood, 2012) or 'having certain sensory discrimination skills for pitch, loudness, rhythm, time, or timbre' (Seashore et al., 1960). Results show that different levels of such formal musical expertise are able to explain variations in intensity of emotional (Dean et al., 2011), aesthetic-perceptual (Farbood, 2012; Pearce et al., 2010) and social experiences with music (Egermann \& McAdams, 2013). Even though newer conceptualizations of musical expertise also encompass more informal dimensions like the intensity of 'active musical engagement' (i.e. keeping track of music and events, spending money on records or downloads) or the acquired habit of intentionally using music to regulate one's own emotions (Müllensiefen et al., 2014), we nevertheless believe that there are several other important dimensions of 'informal musical expertise' that are worth taking into consideration.

By implicitly drawing on the paradigm of the Western classical live concert, the majority of the reported studies and approaches ignore that for most people nowadays, the term 'music' refers to electro-acoustically generated sound rendered by audio or multimedia electronic devices. Indeed, live concert attendances typically form a minority of musical experiences in Western countries (Roose and Stichele, 2010), whilst listening to music by various audio media is highly prevalent (Juslin et al., 2008; Krause et al., 2015). Moreover, the musical material typically stems from very different cultural sources that do not necessarily adhere fully to the Western European art music tradition (North and Hargreaves, 2007; Schäfer and Sedlmeier, 2009). Often, the music listened to is not even a recording of an original live performance - for example, the genres of electronic dance music (EDM) or electro-acoustic music typically rely on complex electronic post-processing of sounds re-sampled from prior recordings, on non-instrumental sounds generated by field recordings or on completely synthetic sounds (Leyshon, 2009; Marontate, 2005; Prior, 2008; Rodgers, 2004; Théberge, 2001). Finally, due to the invention of mobile audio and multimedia

gadgets, music may nowadays can be received and played back with very different material media technologies under different acoustical conditions at very different places and in different social contexts (Greasley and Lamont, 2011;Krause et al., 2015; Lepa, 2013).

In combination, these cultural-technological developments have freed the 'postmodern subject' (Lyotard, 1984) from the social and technological constraints of the live concert, thereby enabling differently situated musical experiences evoked by complex entanglements of socio-spatial contexts with audio technologies' specific affordances (Lepa, 2013) and - last but not least - the differently partaking bodies of social human actors. Hence we want to question the idea of musical expertise in the traditional, formalized sense as being the only relevant form of expertise when it comes to understanding and explaining inter-individual differences in intensity of everyday 
emotional, aesthetic and social experiences with music. This assumption has been problematic since the advent of media reproduction technologies (Benjamin, 2006 [1936]) and gets even more so when positioned alongside the digital mediatization of everyday music listening in the past 20 years and its various cultural and economic consequences (Bull, 2007; Krämer, 2011; Lepa et al., 2014; Molteni and Ordani, 2003; Sandywell and Beer, 2005). In the following, we structure our arguments by drawing on empirical findings from three current music-related research lines that are able to challenge the depicted received view.

\section{Sound}

In its everyday use related to music, the term 'sound' may rather vaguely refer to the acoustical 'footprint' of either a certain instrument, ensemble, genre, performance space, audio production paradigm, time-epoch, playback device, effect-device, compression algorithm, audio emitter or playback room that makes a difference for the musical experience (Moore and Dockwray, 2010; Pras et al., 2009; Pras and Guastavino, 2010; Smudits, 2003; Timmers, 2007; Västfjäll et al., 2002). By drawing on ecological perceptual psychology (Gibson, 1986 [1979]), the quasi-Gestalt quality of these impressions may be explained by the perception and recognition of real existing spectromorphological invariants in the audio signal that specify 'musical affordances' (Windsor and de Bézenac, 2012). These are systematically introduced into the audio material alongside the chain of industrial music production, transmission and reception (Lepa, 2012; Maempel, 2011) and are often well notable, recognizable and discernible for 'experienced listeners'. As anecdotes from everyday life and empirical research from music psychology show, audio engineers, media technicians, hobby musicians and even 'lay people' may obtain the ability to perceive similar formal statistical dependencies within acoustical musical stimuli through mere incidental learning with repeated exposure (Bigand and Poulin-Charronnat, 2006; Hannon and Trainor, 2007; Pearce et al., 2010). This kind of implicit perceptual knowledge about sound establishes an important form of socialization-related musical expertise that will notably change listeners' aesthetic musical experiences as can be demonstrated in experiments that draw on implicit measurements or more open-ended, 'qualitative' question formats (Dibben, 2001; Waterman, 1996).

\section{Materiality}

In everyday life, music playback devices are needed to practically realize the social activity of 'Musicking' (Small, 1998), a term that explicitly includes not only playing an instrument, but also 'mere listening' because it regards the social entirety of any musical event including location, social context, listeners, performers and materiality as a functional whole. Extending this idea by the perspective of social practice theories (Reckwitz, 2002; Schatzki, 2010) and science and technology studies (Pinch, 2008), and as also newer qualitative-interpretive studies demonstrate (Bull, 2007; Magaudda, 2011), the material audio media technologies employed during music listening acts are by no means 'passive' resources just-to-be-turned-on. Instead, they form a constitutive and modulating aspect of each and every music playback 'performance' by changing what can be perceived, felt and done during the social act of Musicking. Hence, a revised concept of musical expertise should also account for the practical knowledge acquired through lifetime about how, where and when to use suitable material artifacts and their varying technological functions to realize the different personal aesthetic and social purposes intended by listening to music. As research on different generations' use of audio media shows (Lepa et al., 2014), 
diverging ways of socialization with different audio media - be them physical or digital artifacts (Leonardi, 2010) - may not only lead to long-time persisting preferences for certain technologies, devices and appliances. They may also lead to very different forms of 'music media orientations', referring to prototypical implicit behavioural-perceptual scripts that pre-structure everyday musical experiences in form of sound-related expectations, different modes of listening and different competencies in terms of accessing and controlling playback as well as registering sound and transmission problems (Lepa et al., 2014). For instance, configuring audio effects and equalizations according to the selected song, or switching reproduction devices in order to get a better fit to the particular music genre listened to may also be regarded as important forms of informal musical expertise since they are based on prior Musicking experiences and may change what is actually possible during listening.

\section{Embodiment}

Finally, the received view of musicology on what musical communication is all about may be challenged. Whilst from the perspective of traditional musicology musical communication would be regarded as the exchange of arbitrary symbols to be interpreted, recent research on embodied music cognition indicates that indexical sign processes, referred to as 'musical gestures', also have to be taken into account in order to fully understand music reception (Leman, 2008). These cannot be formalized by an explicit symbolic 'grammar' as in classical music theory, but can still be 'understood' by human actors through similar neuro-motoric patterns that are automatically evoked when perceiving sounds that refer to familiar sound-producing actions or when imitating movements with one's own body in the form of dancing, swaying or tapping. The ability to recognize musical gestures on basis of such former experiences may as well be considered as a form of music expertise. According to newer theoretical approaches (Maes et al., 2014), this type of knowledge relies on a representational overlap between the planning, the execution and the perception of bodily movements in the human brain. In the end, regardless whether a sound is heard or an accompanying motor event is performed, the (possibly also affective laden) association of the corresponding domain is automatically activated during listening. Thus, individuals who have repeatedly experienced certain movements together with certain types of (musical) sounds will have a different ('embodied') experience when later exposed to the same or similar sounds compared with individuals without these prior experiences (Phillips-Silver and Trainor, 2005). Examples of such embodied musical expertise phenomena also include the ability to 'feel' the action of scratching a needle on a record or 'sense' the hand or foot movements associated with manipulating an equalizer control knob or a guitar floor effect like a Wah-Wah pedal. Furthermore, regular dancing activities may also contribute to likewise-altered musical experiences through associated embodied movement patterns.

In sum, we want to suggest a revised musical expertise that extends the received, traditional dimensions of musical education by drawing on aspects from the depicted research discourses of sound, materiality and embodiment. In so doing, expertise not only develops knowledge, experience and information but is also further nuanced with issues of embodiment, materiality and sound. These elements should generally be considered when conducting future empirical or theoretical work on the experience of everyday music listening, a term that refers foremost to technologically mediated music, as we have argued in the second paragraph. Reasonable dimensions would comprise the width and depth of musical genre knowledge (reaching from classical music of different epochs through non-European genres up to EDM styles) as well as experiences with 
different playback and media formats in order to gain empirical indicators for sonic expertise with mediated music. Furthermore, practical knowledge concerning the different types of audio media technologies (sources, devices and emitters) habitually and biographically used (in terms of 'audio repertoires') would provide empirical indicators for material expertise with mediated music. Finally, practical experiences of the embodied aspects of different types of sound-producing gear and instruments as well as experience of dancing to different genres would help to gain additional empirical indicators for embodied expertise with mediated music. In our view, these three additional dimensions, either in the form of corresponding sampling strategies and indicator variables (when doing experimental or survey research) or in the form of sensitizing concepts and interview guide questions (when doing interpretive or ethnographic research) would help to explain differing intensities in musical experiences in addition to the employment of the well-known empirical indicators for 'formal musical expertise'. After all, our position draws attention to growing convergences between musicology and media and communications research; from our point of view, ecological perception, material practice and embodied experiences are aspects to also be focused on even when studying media use and reception beyond listening to music.

\section{Note}

1. Within this text, we will use the term 'musical expertise' in a broader sense, referring to any type of acquired personal dispositions that might explain inter-individual differences with respect to making or listening to music. This explicitly also includes related conceptualizations such as 'musical ability' (Hallam and Prince, 2003) or 'musical sophistication' (Müllensiefen et al., 2014).

\section{References}

Benjamin W (2006 [1936]) The work of art in the age of mechanical reproduction. In: Durham MG and Kellner DM (eds) Media and Cultural Studies. Keyworks. Maiden: Blackwell Publishing, pp. 18-40.

Bigand E and Poulin-Charronnat B (2006) Are we 'experienced listeners'? A review of the musical capacities that do not depend on formal musical training. Cognition 100(1): 100-130.

Bull M (2007) Sound Moves: iPod Culture and Urban Experience. London: Routledge.

Dean RT, Bailes F, and Schubert E (2011) Acoustic intensity causes perceived changes in arousal levels in music: an experimental investigation. PloS One 6(4): e18591.

Dibben N (2001) What do we hear, when we hear music? Music perception and musical material. Musicae Scientiae 5(2): 161-194.

Egermann H and McAdams S (2013) Empathy and emotional contagion as a link between recognized and felt emotions in music listening. Music Perception 31(2): 139-156.

Farbood M (2012) A parametric, temporal model of musical tension. Music Perception 29(4): 387-428.

Gibson JJ (1986 [1979]) The Ecological Approach to Visual Perception. Boston: Houghton Mifflin.

Greasley AE and Lamont A (2011) Exploring engagement with music in everyday life using experience sampling methodology. Musicae Scientiae 15(1): 45-71.

Hallam S and Prince V (2003) Conceptions of musical ability. Research Studies in Music Education 20(1): $2-22$.

Hannon EE and Trainor LJ (2007) Music acquisition: effects of enculturation and formal training on development. Trends in Cognitive Sciences 11(11): 466-472.

Juslin PN, Liljeström S, Västfjäll D, et al. (2008) An experience sampling study of emotional reactions to music: listener, music, and situation. Emotion 8(5): 668-683.

Krämer B (2011) The mediatization of music as the emergence and transformation of institutions: a synthesis. International Journal of Communication 5: 471-491.

Krause AE, North AC, and Hewitt LY (2015) Music-listening in everyday life: devices and choice. Psychology of Music 43(2): 155-170. 
Leman M (2008) Embodied Music Cognition and Mediation Technology. Cambridge: MIT Press.

Leonardi PM (2010) Digital materiality? How artifacts without matter, matter. First Monday 15(6-7). Available at: http://firstmonday.org/ojs/index.php/fm/article/view/3036 (accessed 29 August 2014).

Lepa S (2012) Was kann das Affordanzkonzept für eine Methodologie der Populärkulturforschung 'leisten'? [English: What does the affordance concept 'afford' with regard to popular culture research methods?]. In: Kleiner MS and Rappe M (eds) Methoden der Populärkulturforschung: Interdisziplinäre Perspektiven auf Film, Fernsehen, Musik, Internet und Computerspiele. Münster: LIT-Verlag, pp. 273-298.

Lepa S (2013) Emotionale Musikrezeption in unterschiedlichen Alltagskontexten: eine wahrnehmungsökologische Perspektive auf die Rolle der beteiligten Medientechnologien. [English: Emotional reception of music in different contexts of everyday life. An ecological perception perspective on the role of the media technologies involved]. In: Schröter J and Vollmar A (eds) Auditive Medienkulturen. Techniken des Hörens und Praktiken der Klanggestaltung. Bielefeld: Transcript, pp. 373-391.

Lepa S, Hoklas A-K, and Weinzierl S (2014) Discovering and interpreting audio media generation units by means of mixed methods: a typological-praxeological approach to the mediatization of everyday music listening. Participations Journal of Audience \& Reception Studies 11(2): 107-238.

Leyshon A (2009) The software slump? Environment and Planning A 41(6): 1309-1331.

Lyotard J-F (1984) The Postmodern Condition: A Report on Knowledge. Manchester: University Press.

Maempel H-J (2011) Musikaufnahmen als Datenquelle der Interpretationsanalyse. [English: Music recordings as a source of data for performance analysis]. In: von Loesch $\mathrm{H}$ and Weinzierl S (eds) Gemessene Interpretation. Computergestützte Aufführungsanalyse im Kreuzverhör der Disziplinen. Mainz: Schott, pp. 157-171.

Maes P-J, Leman M, Palmer C, et al. (2014) Action-based effects on music perception. Frontiers in Theoretical and Philosophical Psychology 4: 1008.

Marontate J (2005) Digital recording and the reconfiguration of music as performance. American Behavioral Scientist 48(11): 1422-1438.

Magaudda P (2011) When materiality 'bites back': digital music consumption practices in the age of dematerialization. Journal of Consumer Culture 11: 15-36.

Molteni L and Ordani A (2003) Consumption patterns, digital technology and music downloading. Long Range Planning 36(4): 389-406.

Moore AF and Dockwray R (2010) The establishment of the virtual performance space in rock. TwentiethCentury Music 5(2): 219-241.

Müllensiefen D, Gingras B, Musil J, et al. (2014) The musicality of non-musicians: an index for assessing musical sophistication in the general population. PLOS ONE 9(2): e89642.

North AC and Hargreaves DJ (2007) Lifestyle correlates of musical preference: 1. Relationships, living arrangements, beliefs, and crime. Psychology of Music 35(1): 58-87.

Ollen JE (2006) A criterion-related validity test of selected indicators of musical sophistication using expert ratings. Doctoral thesis, Ohio State University, Ohio.

Pearce MT, Ruiz M, Kapasi S, et al. (2010) Unsupervised statistical learning underpins computational, behavioural, and neural manifestations of musical expectation. NeuroImage 50(1): 302-313.

Phillips-Silver J and Trainor LJ (2005) Feeling the beat: movement influences infant rhythm perception. Science 308: 1430.

Pinch T (2008) Technology and institutions: living in a material world. Theory and Society 37: 461-483.

Pras A and Guastavino C (2010) Sampling rate discrimination: $44.1 \mathrm{kHz}$ vs. $88.2 \mathrm{kHz}$. Paper presented at the 128th Convention of the Audio Engineering Society (AES), 22-25 May, London, UK.

Pras A, Zimmerman R, Levitin D, et al. (2009) Subjective evaluation of MP3 compression for different musical henres. Paper presented at the 127th Convention of the Audio Engineering Society (AES), 9-12 October, New York, NY, USA.

Prior N (2008) OK computer: mobility, software and the laptop musician. Information, Communication and Society 11(7): 912-932.

Reckwitz A (2002) Toward a theory of social practices. A development in culturalist theorizing. European Journal of Social Theory 5(2): 243-263. 
Rodgers T (2004) On the process and aesthetics of sampling in electronic music production. Organised Sound 8(03): 313-320.

Roose H and Stichele AV (2010) Living room vs. concert hall: patterns of music consumption in Flanders. Social Forces 89(1): 185-207.

Sandywell B and Beer D (2005) Stylistic morphing: notes on the digitisation of contemporary music culture. Convergence: The International Journal of Research into New Media Technologies 11(4): 106-121.

Schatzki TR (2010) Materiality and social life. Nature and Culture 5(2): 123-149.

Schäfer T and Sedlmeier P (2009) From the functions of music to music preference. Psychology of Music 37(3): 279-300.

Seashore CE, Lewis L, and Saetveit JG (1960) Seashore Measures of Musical Talents. New York: The Psychological Corporation.

Small C (1998) Musicking: The Meanings of Performing and Listening. Hanover: University Press of New England.

Smudits A (2003) A journey into sound. Zur Geschichte der Musikproduktion, der Produzenten und der Sounds. [English: A journey into sound. On the history of music production, music producers, and their sounds]. In: von Appen R and Phleps T (eds) Pop Sounds: Klangtexturen in der Pop- und Rockmusik. Basics - Stories - Tracks. Bielefeld: Transcript, pp. 65-94.

Théberge P (2001) 'Plugged in': technology and popular music. In: Frith S, Straw W, and Street J (eds) The Cambridge Companion to Pop and Rock. Cambridge: University Press, pp. 3-25.

Timmers R (2007) Perception of music performance on historical and modern commercial recordings. The Journal of the Acoustical Society of America 122(5): 2872-2880.

Västfjäll D, Larsson P, and Kleiner M (2002) Emotion and auditory virtual environments: affect-based judgments of music reproduced with virtual reverberation times. Cyberpsychology \& Behaviour 5(1): 19-32.

Waterman M (1996) Emotional responses to music: implicit and explicit effects in listeners and performers. Psychology of Music 24(1): 53-67.

Windsor WL and de Bézenac C (2012) Music and affordances. Musicae Scientiae 16(1): 102-120.

\section{Author biographies}

Steffen Lepa is a postdoctoral Researcher at the Audio Communication Group, Technische Universität Berlin and principal investigator on the research project 'Music and Media Survey. Empirical Basic Data and Theoretical Modeling of the Mediatization of Everyday Music Reception in Germany' (German nationalfunded research priority programme 'Mediatized Worlds'), and a member of Berlin cluster-of-excellence research project 'Medium and Emotion. On the emotional effect of music under various media conditions'. His research interests include mediatization research, audio reception, media use, social sciences methodologies, media education, sound design and popular culture.

Anne-Kathrin Hoklas is a Research Associate at the Audio Communication Group, Technische Universität Berlin and a team member on the research project 'Music and Media Survey. Empirical Basic Data and Theoretical Modeling of the Mediatization of Everyday Music Reception in Germany'. Her research interests include cultural sociology, media sociology, praxeological sociology of knowledge and qualitative methods.

Hauke Egermann is a postdoctoral Researcher at the Audio Communication Group, Technische Universität Berlin and principal investigator on the research project ' $3 \mathrm{DMIN}$ - Design, Development and Dissemination of New Musical Instruments'. His research interests include empirical musicology, music psychology, online research methods, social aspects of music reception and embodied music cognition.

Stefan Weinzierl is Head of the Audio Communication Group, Technische Universität Berlin. He is coordinator of the German national research unit 'Simulation and Evaluation of Acoustical Environments (SEACEN)'. His research interests include audio technology, audio communication, musical acoustics, virtual acoustics and empirical musicology. 